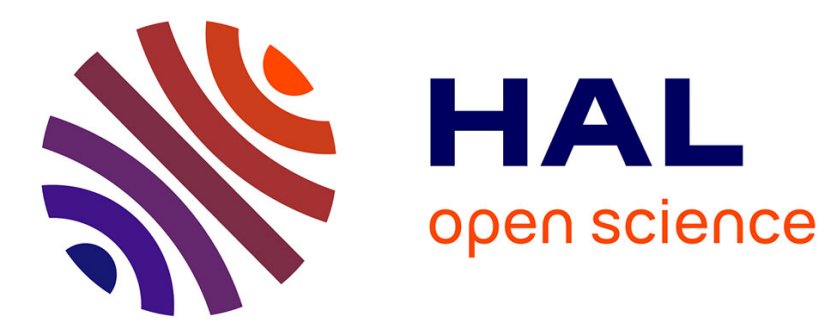

\title{
Dislocation analysis of Ti2AlN deformed at room temperature under confining pressure
}

Antoine Guitton, Anne Joulain, Ludovic Thilly, Christophe Tromas

\section{To cite this version:}

Antoine Guitton, Anne Joulain, Ludovic Thilly, Christophe Tromas. Dislocation analysis of Ti2AlN deformed at room temperature under confining pressure. Philosophical Magazine, 2012, 92 (36), pp.4536-4546. 10.1080/14786435.2012.715250 . hal-03041046

\section{HAL Id: hal-03041046 \\ https://hal.univ-lorraine.fr/hal-03041046}

Submitted on 4 Dec 2020

HAL is a multi-disciplinary open access archive for the deposit and dissemination of scientific research documents, whether they are published or not. The documents may come from teaching and research institutions in France or abroad, or from public or private research centers.
L'archive ouverte pluridisciplinaire HAL, est destinée au dépôt et à la diffusion de documents scientifiques de niveau recherche, publiés ou non, émanant des établissements d'enseignement et de recherche français ou étrangers, des laboratoires publics ou privés. 


\title{
Dislocation analysis of $\mathrm{Ti}_{2} \mathrm{AIN}$ deformed at room temperature under confining pressure
}

\author{
Antoine Guitton, Anne Joulain*, Ludovic Thilly and Christophe Tromas \\ Pprime Institute, Department of Materials Physics and Mechanics, UPR 3346, CNRS, \\ University of Poitiers, ENSMA, SP2MI, Boulevard Marie et Pierre Curie, \\ BP 30179, 86962 Futuroscope Chasseneuil Cedex, France
}

(Received 4 April 2012; final version received 19 July 2012)

\begin{abstract}
Compression experiments of the brittle MAX phase $\mathrm{Ti}_{2} \mathrm{AlN}$ were performed under confining gas pressure at room temperature. Subsequently, a complete dislocation analysis was performed by transmission electron microscopy. In particular, the Burgers vectors and the dislocation lines were studied via the weak beam technique: dislocation reactions are reported for the first time in a MAX phase, as well as dipole interactions. Footprints of a high lattice friction were also observed. All these features point towards classical dislocation activity, eventually leading to hardening.
\end{abstract}

Keywords: MAX phases; $\mathrm{Ti}_{2} \mathrm{AlN}$; dislocations; transmission electron microscopy; plasticity

\section{Introduction}

The ternary nitride $\mathrm{Ti}_{2} \mathrm{AlN}$ is a hexagonal layered compound belonging to the family of $\mathrm{M}_{n+1} \mathrm{AX}_{n}$ phases, where $n=1-3, \mathrm{M}$ is a transition metal, $\mathrm{A}$ is an A-group element and $\mathrm{X}$ is nitrogen or carbon [1]. The lattice anisotropy $(c / a \approx 4.5)$ and the lamellar structure of $\mathrm{Ti}_{2} \mathrm{AlN}$, as for all MAX phases, have a major impact on deformation mechanisms via the formation of kink and shear bands and eventually grain delaminations, leading to brittle-like behaviour below $\sim 800^{\circ} \mathrm{C}[1,2]$.

The deformation mechanism of MAX phases is based on dislocations movement. From energy considerations, Barsoum et al. [3] suggested that only basal dislocations play a role in the plastic behaviour of MAX phases; due to the anisotropic and lamellar lattice, nucleation of dislocations is supposed to occur only in the basal plane. To date, the majority of transmission electron microscopy (TEM) studies have concerned deformed $\mathrm{Ti}_{3} \mathrm{SiC}_{2}$ polycrystals and have revealed the presence of perfect dislocations belonging to the basal plane (0001) with a Burgers vector $\boldsymbol{b}=1 / 3\langle 11-20\rangle$ [4-6]. Moreover, dislocations are organised into pile-ups (on the same basal plane) or into walls (perpendicular to basal planes). Recent experimental studies via atomic force microscopy (AFM) or TEM, have demonstrated that out-of-basal-plane dislocations also exist in MAX phases, although the nucleation and gliding of

\footnotetext{
*Corresponding author. Email: anne.joulain@univ-poitiers.fr
} 
dislocations in the basal plane is probably the main deformation mechanism $[7,8]$. Observations of stacking faults is the second major microstructural feature, the fault vector being $\boldsymbol{R}=(000 \delta)$, but their role in the deformation mechanism is yet unclear [4,7,9]. According to Barsoum et al. [2], the formation of dislocation walls is at the origin of the kink band (KB) formation: the proposed elementary micro-mechanism, the so-called incipient kink bands (IKBs) [10], is associated to nucleation of the parallel basal dislocation loops. No direct evidence of these IKBs has been yet obtained. The KBs give rise to misorientation of the lattice with a so-called 'stovepipe' shape. For high deformation, this mechanism leads to buckling and delamination cracks within individual grains [2]. According to the KB formation model, the mechanical properties of MAX phase materials is thus mainly ascribed to basal plane dislocations, which are able to freely glide without dislocation reactions, allowing dislocation wall formation.

In this paper, we present a TEM analysis of $\mathrm{Ti}_{2} \mathrm{AlN}$ material synthetised by powder metallurgy and compressed under confining pressure at room temperature. The use of a weak beam technique allows for detailed analysis of dislocations configurations. In particular, the Burgers vector and the dislocation line can be determined. All results are discussed within the framework of comprehension of the deformation mechanisms of MAX phases.

\section{Experimental details}

\subsection{Synthesis}

Fully dense samples were prepared by using hot isostatic pressing (HIP). To synthesise $\mathrm{Ti}_{2} \mathrm{AlN}$ polycrystalline samples, Ti (grain size $<149 \mu \mathrm{m}$ ) and AlN (grain size $<10 \mu \mathrm{m}$ ) powders were mixed in stoichiometric proportions and placed into a hot isostatic press where they are heated up to $1450^{\circ} \mathrm{C}$ under a pressure of $80 \mathrm{MPa}$.

After the HIPing process, porosity measurements and X-ray diffraction (XRD) were carried out, respectively, with a He pycnometer and a Bruker D8 diffractometer: a porosity of less than $1 \%$ was measured while the lattice parameters calculated by Rietveld analysis (with MAUD software [11]) were $a=2.98846 \pm 7.10^{-5} \AA$ and $c=13.5917 \pm 5 \cdot 10^{-4} \AA$. Moreover, EDX analyses were performed and showed the presence of a small amount of $\mathrm{TiN}$ and $\mathrm{Al}_{2} \mathrm{O}_{3}$, not detectable by XRD. Their volume fraction was estimated to be less than $5 \%$.

$\mathrm{Ti}_{2} \mathrm{AlN}$ samples were cut into parallelepipeds with dimensions of about $3.8 \times 2.5 \times 7.3 \mathrm{~mm}^{3}$ and all faces are carefully polished, one of the lateral faces being chemo-mechanically polished to reveal the grains. The SEM observations performed on as-grown samples enabled one to determine that the grains have an average area of $211 \mu \mathrm{m}^{2}$ (corresponding to an average size of $15 \mu \mathrm{m}$ if one assumes a square shape).

\subsection{Compression test under confining pressure}

To perform the uniaxial compression tests in the Paterson apparatus, each parallelipedic sample must be inserted into an annealed aluminium cylindrical jacket to respect the cylindrical symmetry of the compression device [12]. In the 
present case, the deformation tests were performed at room temperature under a confining argon pressure of $320 \mathrm{MPa}$ and at a strain rate of $5 \times 10^{-5} \mathrm{~s}^{-1}$. As the recorded stress-strain curves were associated with the assembly "sample + aluminium jacket," the stress-strain data of the $\mathrm{Ti}_{2} \mathrm{AlN}$ sample alone were extracted by a deconvolution procedure based on the rule of mixtures, as described in [13]. After deformation, the $\mathrm{Ti}_{2} \mathrm{AlN}$ samples were removed from the aluminium jackets to carry out TEM analysis.

\subsection{Thin foils preparation}

The TEM foils were cut at $45^{\circ}$ from the compression axis and thinned by mechanical polishing down to $30 \mu \mathrm{m}$ by the Tripod technique, followed by dimpling down to a few microns. Subsequently, the thin foils were glued on molybdenum grids and further thinned with a precision ion polishing system (PIPS from Gatan). TEM weak beam and extinction techniques were performed on a Phillips CM20 microscope operated at $200 \mathrm{kV}$.

\section{Results}

\subsection{Compression under confining pressure}

Thanks to the confining pressure, the closure of cracks inside the brittle sample allowed reaching a plastic strain of $5.15 \%$ after return to room pressure and removal of the $\mathrm{Ti}_{2} \mathrm{AlN}$ sample from the $\mathrm{Al}$ jacket. The stress-strain curve of one $\mathrm{Ti}_{2} \mathrm{AlN}$ sample is presented in Figure 1. This curve shows elastic and plastic regimes with a maximum compressive stress of $1.3 \mathrm{GPa}$. A hardening regime was followed by a softening regime tending to zero hardening.

\subsection{TEM observations}

Figure 2 shows an area of interest with typical microstructure observed in deformed $\mathrm{Ti}_{2} \mathrm{AlN}$; the diffraction condition is such that electrons are perpendicular to the basal plane and the used diffracting vector is $\boldsymbol{g}_{1}=-1-120$. In such conditions, all dislocations and stacking faults generally reported in MAX phases $(\boldsymbol{b}=1 / 3\langle 11-20\rangle$ and $\boldsymbol{R}=1 / 3\langle 000 \delta\rangle$ ) are expected to be in contrast [7]. Figure 2 illustrates the large variety of dislocation directions and configurations. No stacking faults are observed here. The white squares in Figure 2 emphasise the configurations studied in detail below and presented in Figures 3-6. All these configurations have been observed using the same $\boldsymbol{g}$ vectors: $\boldsymbol{g}_{1}=-1-120, \boldsymbol{g}_{2}=10-1-3, \boldsymbol{g}_{3}=1-10-3, \boldsymbol{g}_{4}=-101-3$ and $\boldsymbol{g}_{5}=0-11-3$.

Figure 3 presents the dislocations of configuration A. The weak beam contrast enables one to determine the Burgers vector from extinction conditions $(\boldsymbol{g} . \boldsymbol{b}=0)$ using different diffracting vectors $\boldsymbol{g}$. Figure $3 \mathrm{a}-\mathrm{d}$ show micrographs obtained with $\boldsymbol{g}_{1}$, $\boldsymbol{g}_{2}, \boldsymbol{g}_{3}$ and $\boldsymbol{g}_{5}$. Comparison of these images shows that five dislocation segments can be distinguished with different extinction conditions corresponding then to different Burgers vectors. For instance, in Figure 3d, segment 5 is clearly out of contrast with the diffracting vector $\boldsymbol{g}_{5}=0-11-3$. Consequently, the contrasts of segment 5 are 


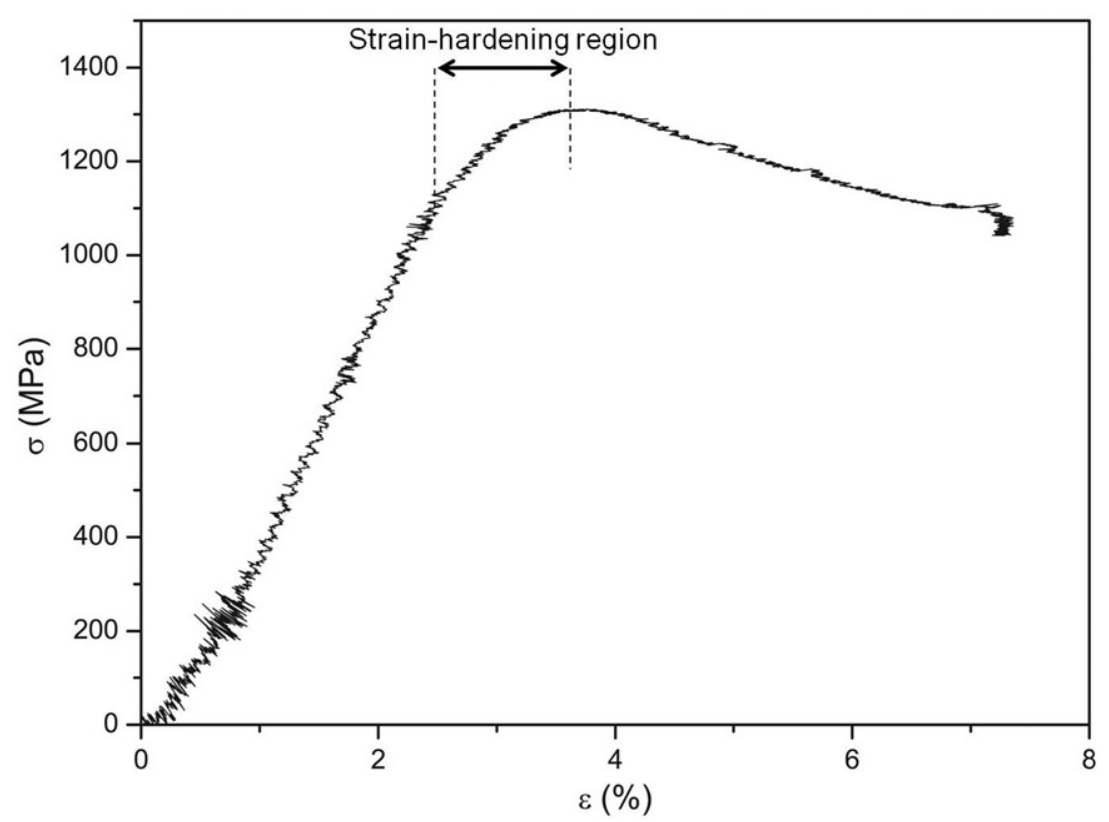

Figure 1. Stress-strain curve of $\mathrm{Ti}_{2} \mathrm{AlN}$ deformed at room temperature under confining pressure $(320 \mathrm{MPa})$.

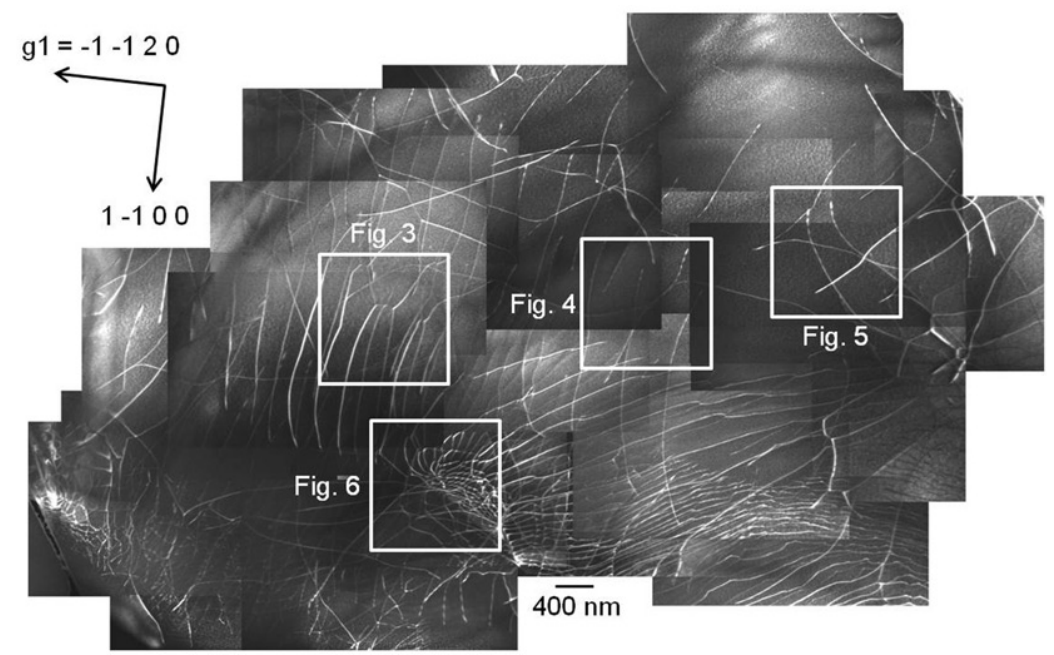

Figure 2. TEM micrograph showing a typical landscape observed in deformed $\mathrm{Ti}_{2} \mathrm{AlN}$, viewed using the diffracting vector $\boldsymbol{g}_{1}=-1-120$ in the (0001) zone axis. The white squares localise the studied areas presented in Figures 3, 4, 5 and 6.

consistent with a Burgers vector $\boldsymbol{b}_{3}= \pm 1 / 3[-2110]$. This extinction analysis was repeated for each dislocation segment constituting configuration $\mathrm{A}$, and is presented in Table 1. The reported configuration $\mathrm{A}$ appears to be a classical node reaction between two dislocations $\boldsymbol{b}_{1}+\boldsymbol{b}_{2}=\boldsymbol{b}_{3}(2+3=5$ and $1+4=5)$ with $\boldsymbol{b}_{1}= \pm \frac{1}{3}[-12-10]$, 

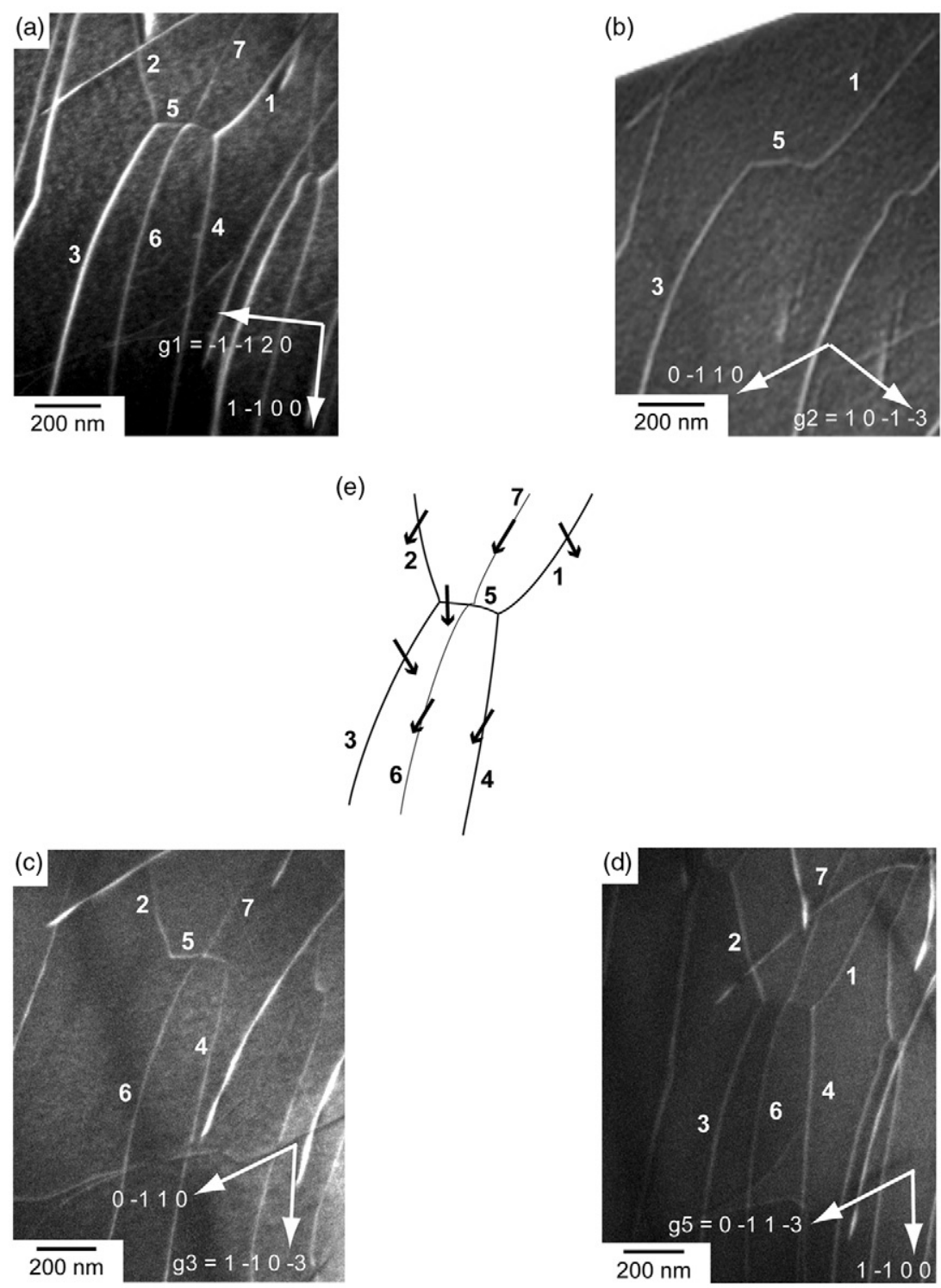

Figure 3. TEM micrographs of configuration A showing reaction between two dislocations observed with (a) $\boldsymbol{g}_{1}=-1-120$, (b) $\boldsymbol{g}_{2}=10-1-3$, (c) $\boldsymbol{g}_{3}=1-10-3$ and (d) $\boldsymbol{g}_{5}=0-11-3$. (e) Schematic of the reaction. The Burgers vector direction is symbolised by the arrows.

$\boldsymbol{b}_{2}= \pm 1 / 3[-1-120]$ and $\boldsymbol{b}_{3}= \pm 1 / 3[-2110]$ lying in the same basal plan, as schematised in Figure $3 \mathrm{e}$. Concerning the dislocation line $\boldsymbol{\ell}$, it was determined as the intersection between the different planes which contain the dislocation and can be determined from observation of the dislocation with different crystal orientation. The dislocation lines $\ell$ is reported in Table 1 for each segment; surprisingly, the dislocation 

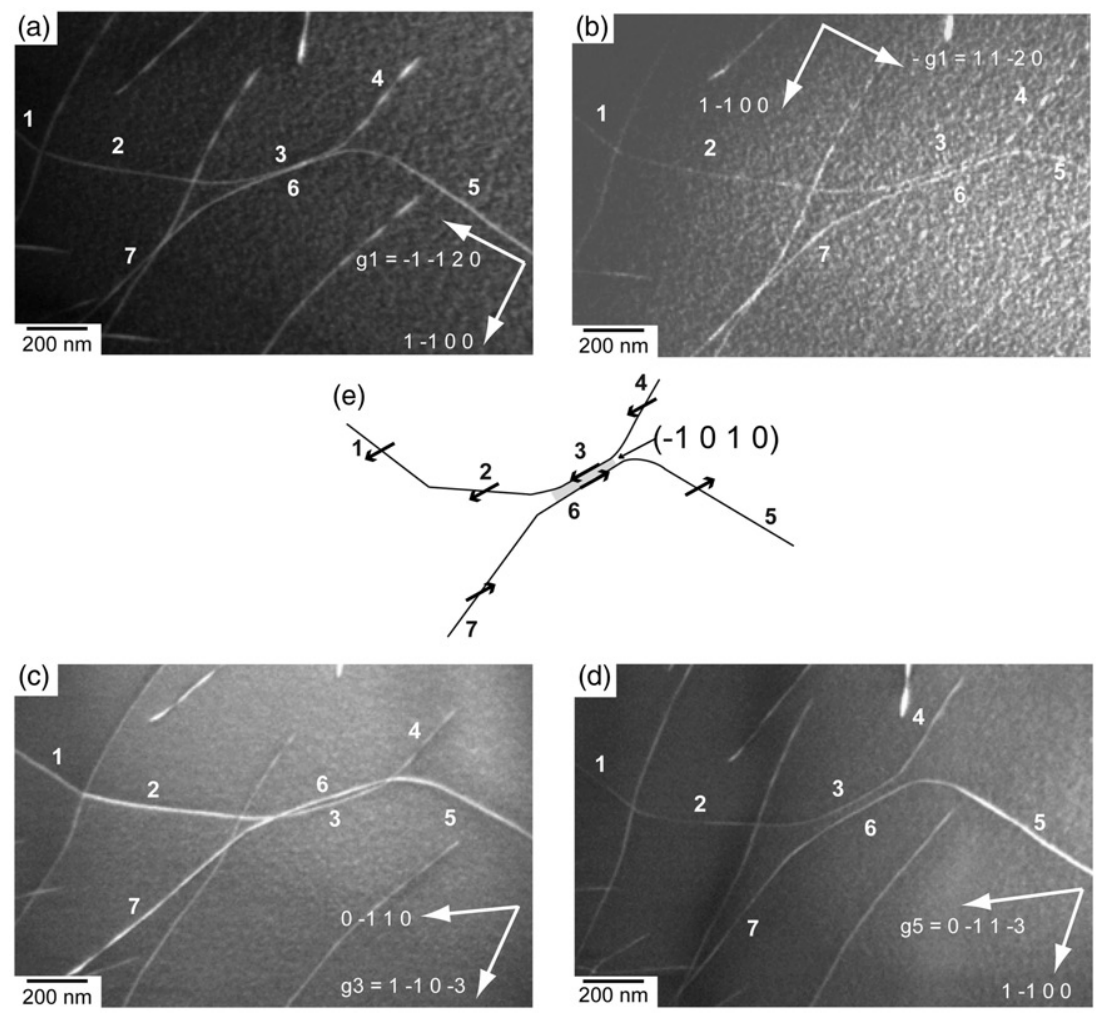

Figure 4. TEM micrographs of configuration B showing a dipole interaction observed with (a) $g_{1}=-1-120$, (b) $-g_{1}=11-20$, (c) $g_{3}=1-10-3$ and (d) $g_{5}=0-11-3$. (e) Schematic of the dipole. The Burgers vector direction is symbolised by the arrows. The dipole plane is (-1010).

nature is never random: values of angle between dislocation line $\boldsymbol{\ell}$ and Burgers vector $\boldsymbol{b}, \alpha=(\boldsymbol{b} ; \boldsymbol{\ell})$, are always observed to correspond to pure screw $\left(0^{\circ}\right), 30^{\circ}$ or $60^{\circ}$ configurations. Such results are reported for the first time in MAX phases.

Configuration B is presented in Figure 4. The micrographs are observed with different $\boldsymbol{g}$ vectors $\left(\boldsymbol{g}_{1}=-1-120,-\boldsymbol{g}_{1}=11-20, \boldsymbol{g}_{3}=1-10-3\right.$ and $\left.\boldsymbol{g}_{5}=0-11-3\right)$. Analysis of the dislocation segment contrasts and the dislocation lines are presented in Table 2. All dislocation segments are out of contrast with the same diffracting vector $\boldsymbol{g}_{4}=-101-3$ (not shown here). Therefore, the Burgers vector is unique for all segments of the configuration and is consistent with $\boldsymbol{b}= \pm 1 / 3[-12-10]$. Moreover, when tilting the thin foil (Figure 4a, c and d), one observes a finite distance between segments 3 and 6 . Additionally, images of the segments 3 and 6 obtained with $\boldsymbol{g}_{1}$ (Figure $4 \mathrm{a}$ ) and its opposite (Figure 4b) show that both contrasts are displaced from one side of the dislocation position to the other side. Combining all these data leads to the conclusion that segments 3 and 6 form a dislocations dipole lying in the prismatic plane $(-1010)$, with Burgers vector being, respectively, $\boldsymbol{b}= \pm 1 / 3[-12-10]$ and $-\boldsymbol{b}= \pm 1 / 3[1-210]$. The fact that the dipole does not annihilate suggests that dislocation cannot cross-slip from the basal to the prismatic plane. Abrupt direction 

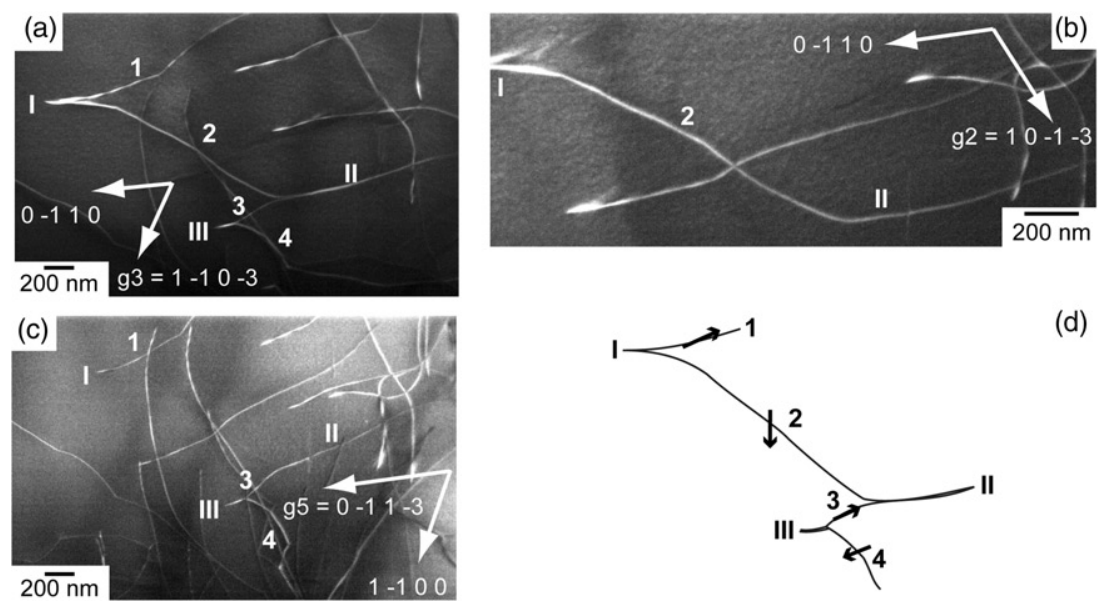

(d)

Figure 5. TEM micrographs of configuration $\mathrm{C}$ showing dislocation interactions observed with (a) $\boldsymbol{g}_{3}=1-10-3$, (b) $\boldsymbol{g}_{2}=10-1-3$ and (c) $\boldsymbol{g}_{5}=0-11-3$. (d) Schematic of the interaction. The Burgers vector direction is symbolised by the arrows.

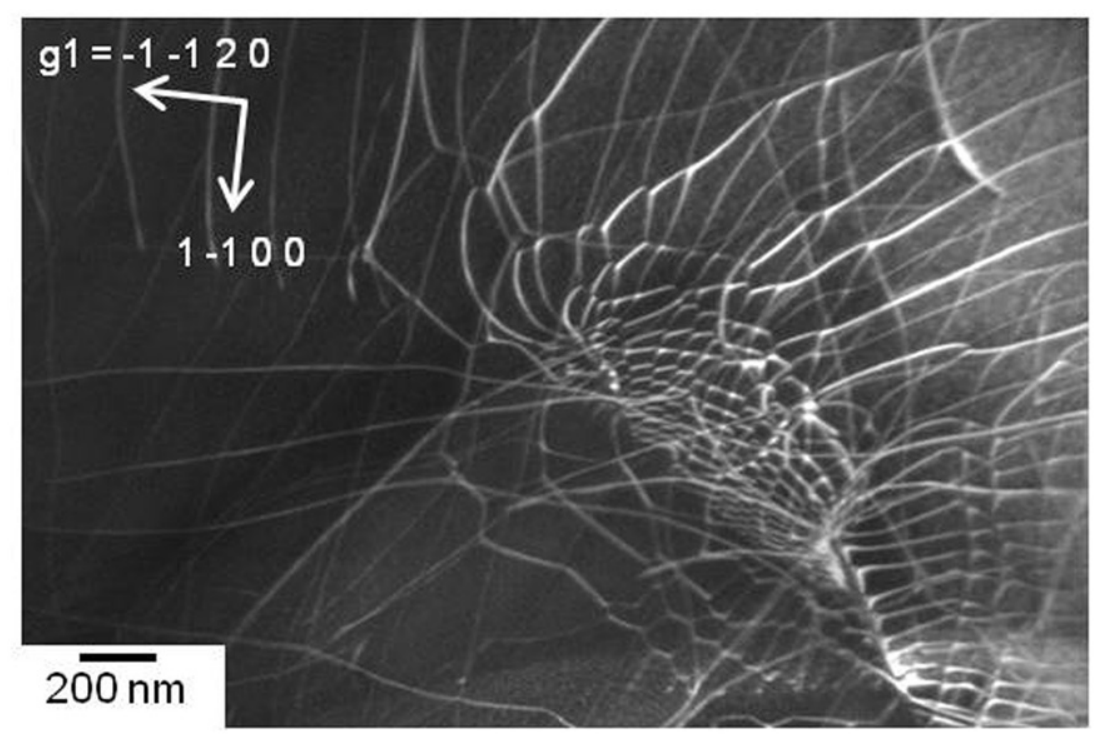

Figure 6. TEM micrograph showing complex interactions between dislocations, producing cells (observed with $g_{1}=-1-120$ ).

changes are observed between the different straight segments, their nature corresponding again to pure screw $\left(0^{\circ}\right), 30^{\circ}$ or $60^{\circ}$ dislocations.

The last configuration, C, presented in Figure 5, shows another set of dislocation interactions that could be observed many times in the thin foil. For each dislocation segment, extinction conditions and dislocation line data are summarised in Table 3. 
Table 1. Contrasts of dislocations under different diffraction conditions (configuration A, Figure 3).

\begin{tabular}{|c|c|c|c|c|c|c|c|c|}
\hline & $g_{1}=-1-120$ & $g_{2}=10-1-3$ & $g_{3}=1-10-3$ & $g_{4}=-101-3$ & $g_{5}=0-11-3$ & $\begin{array}{l}\text { Burgers } \\
\text { vector } \boldsymbol{b}\end{array}$ & Line $\ell$ & $\alpha\left(^{\circ}\right)$ \\
\hline 1 & $\checkmark$ & $\checkmark$ & $x$ & $\checkmark$ & $\checkmark$ & $\pm 1 / 3[-1-120]$ & {$[1-210]$} & 60 \\
\hline 2 & $\checkmark$ & $x$ & $\checkmark$ & $x$ & $\checkmark$ & $\pm 1 / 3[-12-10]$ & [2-1-10] & 60 \\
\hline 3 & $\checkmark$ & $\checkmark$ & $x$ & $\checkmark$ & $\checkmark$ & $\pm^{1 / 3}[-1-120]$ & {$[1-210]$} & 60 \\
\hline 4 & $\checkmark$ & $x$ & $\checkmark$ & $x$ & $\checkmark$ & $\pm 1 / 3[-12-10]$ & {$[1-100]$} & 30 \\
\hline 5 & $\checkmark$ & $\checkmark$ & $\checkmark$ & $\checkmark$ & $x$ & $\pm \frac{1}{3}[-2110]$ & {$[-1-120]$} & 60 \\
\hline 6 & $\checkmark$ & $x$ & $\checkmark$ & $x$ & $\checkmark$ & $\pm 1 / 3[-12-10]$ & {$[1-210]$} & 0 \\
\hline 7 & $\checkmark$ & $x$ & $\checkmark$ & $x$ & $\checkmark$ & $\pm 1 / 3[-12-10]$ & [1-210] & 0 \\
\hline
\end{tabular}

Notes: $\checkmark$ : in contrast; $\boldsymbol{X}$ : out of contrast; $\boldsymbol{\ell}$ : dislocation line; $\alpha$ : the absolute value of the angle between $\boldsymbol{b}$ and $\boldsymbol{\ell}$.

Table 2. Contrasts of dislocations under different diffraction conditions (configuration B, Figure 4).

\begin{tabular}{|c|c|c|c|c|c|c|c|c|}
\hline & $-g_{1}=-1-120$ & $g_{1}=11-20$ & $g_{3}=1-10-3$ & $g_{4}=-101-3$ & $g_{5}=0-11-3$ & $\begin{array}{l}\text { Burgers } \\
\text { vector } \boldsymbol{b}\end{array}$ & Line $\ell$ & $\alpha\left(^{\circ}\right)$ \\
\hline 1 & $\checkmark$ & $\checkmark$ & $\checkmark$ & $x$ & $\checkmark$ & $\pm 1 / 3[-12-10]$ & {$[-1-120]$} & 60 \\
\hline 2 & $\checkmark$ & $\checkmark$ & $\checkmark$ & $x$ & $\checkmark$ & $\pm 1 / 3[-12-10]$ & {$[0-110]$} & 30 \\
\hline 3 & $\checkmark$ & $\checkmark$ & 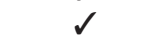 & $x$ & $\checkmark$ & $\pm 1 / 3[-12-10]$ & {$[1-210]$} & 0 \\
\hline 4 & $\checkmark$ & $\checkmark$ & $\checkmark$ & $x$ & $\checkmark$ & $\pm 1 / 3[-12-10]$ & {$[1-100]$} & 30 \\
\hline 5 & $\checkmark$ & $\checkmark$ & $\checkmark$ & $x$ & $\checkmark$ & $\pm 1 / 3[1-210]$ & {$[-1-120]$} & 60 \\
\hline 6 & $\checkmark$ & $\checkmark$ & $\checkmark$ & $x$ & $\checkmark$ & $\pm 1 / 3[1-210]$ & {$[1-210]$} & 0 \\
\hline 7 & $\checkmark$ & $\checkmark$ & $\checkmark$ & $x$ & $\checkmark$ & $\pm \frac{1}{3}[1-210]$ & {$[1-100]$} & 30 \\
\hline
\end{tabular}

Notes: $\checkmark \mathfrak{V}$ : in contrast; $\boldsymbol{X}$ : out of contrast; $\boldsymbol{\ell}$ : dislocation line; $\alpha$ : the absolute value of the angle between $\boldsymbol{b}$ and $\boldsymbol{\ell}$.

Table 3. Contrasts of dislocations under different diffraction conditions (configuration C, Figure 5).

\begin{tabular}{|c|c|c|c|c|c|c|c|c|}
\hline & $g_{1}=-1-120$ & $g_{2}=10-1-3$ & $g_{3}=1-10-3$ & $g_{4}=-101-3$ & $g_{5}=0-11-3$ & $\begin{array}{l}\text { Burgers } \\
\text { vector } \boldsymbol{b}\end{array}$ & Line $\ell$ & $\alpha\left(^{\circ}\right)$ \\
\hline 1 & $\checkmark$ & $x$ & $\checkmark$ & $x$ & $\checkmark$ & $\pm 1 / 3[-12-10]$ & [0-110] & 30 \\
\hline 2 & $\checkmark$ & $\checkmark$ & $\checkmark$ & $\checkmark$ & $x$ & $\pm 1 / 3[2-1-10]$ & {$[-1-120]$} & 60 \\
\hline 3 & $\checkmark$ & $x$ & $\checkmark$ & $x$ & $\checkmark$ & $\pm 1 / 3[-12-10]$ & [1-210] & 0 \\
\hline 4 & $\checkmark$ & $x$ & $\checkmark$ & $x$ & $\checkmark$ & $\pm^{1 / 3}[1-210]$ & {$[-1-120]$} & 60 \\
\hline I & $\checkmark$ & $\checkmark$ & $\checkmark$ & $\checkmark$ & $\checkmark$ & $\begin{array}{l} \pm 1 / 3[2-1-10] \\
\pm 1 / 3[-12-10]\end{array}$ & [0-110] & $\begin{array}{l}90 \\
30\end{array}$ \\
\hline II & $\checkmark$ & $\checkmark$ & $\checkmark$ & $\checkmark$ & $\checkmark$ & $\begin{array}{l} \pm^{1 / 3}[2-1-10] \\
\pm^{1 / 3}[-12-10]\end{array}$ & [0-110] & $\begin{array}{l}90 \\
30\end{array}$ \\
\hline III & $\checkmark$ & $x$ & $\checkmark$ & $x$ & $\checkmark$ & $\begin{array}{l} \pm^{1 / 3}[-12-10] \\
\pm^{1 / 3}[1-210]\end{array}$ & [0-110] & 30 \\
\hline
\end{tabular}

Notes: $\checkmark$ : in contrast; $\boldsymbol{X}$ : out of contrast; $\boldsymbol{\ell}$ : dislocation line; $\alpha$ : the absolute value of the angle between $\boldsymbol{b}$ and $\boldsymbol{\ell}$. I, II and III are configurations with two dislocations. 
The studied network is actually composed of several dislocation arrays belonging to parallel basal planes: the different dislocation families strongly interact but do not react. For instance, regions I or II are both composed of two segments with different Burgers vectors: $\boldsymbol{b}_{1}= \pm 1 / 3[2-1-10]$ and $\boldsymbol{b}_{2}= \pm 1 / 3[-12-10]$ aligned in parallel basal planes. The origin of these strong interactions is unclear: the driving force could be either the formation of a node $\left(\boldsymbol{b}_{1}+\boldsymbol{b}_{2}\right)$ that is frustrated by the difficulty for the dislocations to cross-slip or the alignment of dislocations along specific directions associated to $30^{\circ}$ and edge character (see Table 3 ). Note that region III corresponds to a dislocation dipole, as observed in previous configuration.

\section{Discussion}

First of all, TEM micrographs unambiguously show that $\mathrm{Ti}_{2} \mathrm{AlN}$ was successfully plastically deformed at room temperature. The wide variety of dislocation directions and configurations is due to the confining pressure that closes cracks to the favour of the plasticity during compression with the Paterson apparatus. Note that, under room pressure condition, only the rise in temperature enables reaching significant plasticity before intergranular failure: at room temperature, the plastic strain is usually almost zero and the maximum compressive stress is of the order of $400 \mathrm{MPa}$, compared to the $1.3 \mathrm{GPa}$ recorded here [14].

An overview of the TEM observations reveals that a large number of dislocation interactions exist between the numerous dislocation arrays produced inside the grain. In other words, isolated dislocations are almost never observed. More precisely, many configurations correspond to dislocation reactions forming nodes, a situation that is very common in deformed hexagonal materials [15] but reported for the first time in MAX phases. Actually, such interactions have been observed but not analysed in detail in deformed $\mathrm{Ti}_{4} \mathrm{AlN}_{3}$ and $\mathrm{Ti}_{3} \mathrm{AlC}_{2}[7,16]$. As a rule, all the observed dislocation families belong to the basal plane and strongly interact with each other to form nodes, dipoles (Figure 4) or alignments along common directions.

An important result of the present study is the systematic observation of dislocations aligning along directions associated to screw, $30^{\circ}, 60^{\circ}$ or edge character. Recent $a b$ initio simulations [17,18] allowed for the calculation of the elastic constants $\left(C_{i j}\right)$ of $\mathrm{Ti}_{2} \mathrm{AlN}$, revealing a rather low elastic anisotropy in the basal planes. In light of these results, the observed dislocation alignments along specific orientations could be the sign of an elevated lattice friction rather than the effect of elastic anisotropy. The combination of all these features is illustrated by Figure 6, where a high density of nodes and alignments result in the formation of complex and very dense hexagonal cells that are very similar to those observed in severely deformed metals [15]. Work in progress suggests that these features are very common to the deformation landscape of MAX phases. Dislocation reactions may play an important role in deformation mechanism; in particular the presence of dense dislocations networks may hinder displacement of dislocations walls or piles-up. Combined with the ease of the dislocation reaction, this preferential alignment along specific crystallographic directions may explain the strain hardening regime observed 
in the stress-strain curves of the MAX phases, leading to an upper compressive stress followed by mechanical softening associated to damage production and eventually leading to brittle-like failure (especially at low temperature where thermally activated processes are not favoured).

\section{Conclusion}

From TEM analyses, the deformation microstructure of RT-deformed $\mathrm{Ti}_{2} \mathrm{AlN}$ was studied, giving new insights into the deformation mechanisms of MAX phases. First, compression tests at room temperature under confining gas pressure were performed up to large amounts of plastic strain. This high strain gives access to original microstructures never studied before for this kind of materials.

Second, classical node reactions between dislocations lying in the basal plane and dipole interactions were observed. Moreover, when interacting, dislocations align along specific directions leading to segments with screw, $30^{\circ}, 60$ or edge character, indicative of an elevated lattice friction. The ease of the dislocation reaction and the preferential alignment along specific crystallographic directions have to be related to the strain hardening observed in the stress-strain curves of the MAX phases. Such features shed new light on our comprehension of the deformation mechanisms.

\section{Acknowledgements}

The authors thank P. Carrez for fruitful discussion, and A.-M. Archambault and A. Baudet for their technical assistance.

\section{References}

[1] M. Barsoum and T. El-Raghy, Am. Sci. 89 (2001) p.334.

[2] M. Barsoum, L. Farber and T. El-Raghy, Metall. Mater. Trans. A 30 (1999) p.1727.

[3] M. Barsoum and M. Radovic, Ency. Mater. Sci. Technol. 16 (2004) p.1.

[4] L. Farber, I. Levin and M. Barsoum, Philos. Mag. Lett. 79 (1999) p.1673.

[5] B. Kooi, R. Poppen and N. Carvalho, J. Hosson and M. Barsoum, Acta Mater. 51 (2003) p.2859.

[6] M. Barsoum and M. Radovic, Annu. Rev. Mater. Res. 41 (2011) p.195.

[7] A. Joulain, L. Thilly and J. Rabier, Philos. Mag. 88 (2008) p.1307.

[8] C. Tromas, P. Villechaise, V. Gauthier-Brunet and S. Dubois, Philos. Mag. 91 (2010) p. 1265 .

[9] Z. Lin, M. Li and Y. Zhou, J. Mater. Sci. Technol. 23 (2007) p.145.

[10] M. Barsoum, T. Zhen, S. Kalidindi, M. Radovic and A. Murugaiah, Nature Mater. 2 (2003) p.107.

[11] M. Ferrari and L. Lutterotti, J. Appl. Phys. 76 (1994) p.11.

[12] M. Paterson, J. Rock Mech. Miner. Sci. 7 (1970) p.517.

[13] A. Mussi, L. Thilly, J. Rabier and J.-L. Demenet, Mater. Sci. Eng. A 478 (2008) p.140.

[14] Z. Zhang and Z. Sun, Mater. Sci. Eng. A 408 (2005) p.64. 
[15] D. Hull and D. Bacon, Introduction to Dislocations, Butterworth-Heinemann, Oxford, 2001.

[16] G. P. Bei, Synthesis, microstructural characterization and mechanical properties of MAX phases, $\mathrm{PhD}$ thesis, University of Poitiers, 2011.

[17] M.F. Cover, O. Warschkow, M.M.M. Bilek and D. McKenzie, Adv. Eng. Mater. 10 (2008) p.935.

[18] T. Duong, S. Gibbons, R. Kinra and R. Arróyave, J. App. Phys. 110 (2011) p.093504. 